\title{
A Modelagem Matemática na Educação Infantil: uma experiência vivida
}

\author{
Mathematical Modeling in early Childhood Education: a lived experience
}

\author{
Cibelli Batista Belo \\ Dionisio Burak
}

\begin{abstract}
Resumo: A Educação Infantil é a primeira etapa da Educação Básica e é considerada fundamental para o desenvolvimento cognitivo, afetivo, social e físico da criança. A Modelagem Matemática, sob o ponto de vista da Educação Matemática, se apresenta como uma prática pedagógica capaz de possibilitar esse desenvolvimento. Este artigo tem como objetivo descrever as contribuições da Modelagem Matemática no desenvolvimento das crianças em uma turma de Pré I, entre 4 a 5 anos. Participaram da investigação, dez crianças de uma escola pública. Os dados foram obtidos por meio de observações, fotos e filmagens. A análise foi realizada com base nos dados coletados. Descreve como as práticas foram concretizadas e as modificações necessárias ocorridas nas suas etapas quando desenvolvidas em uma turma de Pré I. Os resultados mostram as contribuições dessa prática pedagógica para o desenvolvimento das crianças, tornando-as mais participativas, autônomas e ressaltando a importância do diálogo e a interação entre elas.
\end{abstract}

Palavras-chave: Aprendizagens. Educação Infantil. Modelagem na Educação Matemática.

Abstract: Early Childhood Education is the first stage of Basic Education and is considered fundamental for the child's cognitive, affective, social and physical development. Mathematical Modeling, from the point of view of Mathematics Education, presents itself as a pedagogical practice capable of enabling this development. This article aims to describe the contributions of Mathematical Modeling in the development of children in a Pre I class, between 4 and 5 years old. Ten children from a public school participated. The data were obtained through observations, photos and filming. The analysis was performed based on the collected data. Describes how the practices were implemented and the necessary changes that occurred in their stages when developed in a class of Pre I. The results show the contributions of this pedagogical practice to the development of children, making them more participatory, autonomous and emphasizing the importance of dialogue and the interaction between them.
Cibelli Batista Belo Doutoranda em Educação em Ciências e em Matemática pela Universidade Federal do Paraná (UFPR). Professora da Secretaria Municipal de Irati. Paraná, Brasil.

iD orcid.org/0000-0001-7782-3361 $\bowtie$ cibellibatistabelo@gmail.com

Dionisio Burak Doutor em Educação. Professor do Programa de Pós-Graduação em Ensino de Ciências Naturais e Matemática da Universidade Estadual do Centro-Oeste (UNICENTRO). Paraná, Brasil. iD orcid.org/0000-0002-1345-1113 $\bowtie$ dioburak@yahoo.com.br Recebido em 10/03/2020 Aceito em 27/04/2020 Publicado em 08/05/2020

Keywords: Learning. Early Childhood Education. Modeling in Mathematics Education.

\section{Introdução}

A Educação Infantil, primeira etapa da Educação Básica, é ofertada às crianças de 0 a 5 anos, em escolas públicas ou privadas. Esta fase é muito importante para o desenvolvimento integral, ou seja, cognitivo, emocional, social e físico da criança. As crianças aprendem a partir de 
interações e brincadeiras, conforme Horn (2017) e a Base Nacional Comum Curricular (BRASIL, 2017). Por meio de práticas pedagógicas, elas aprendem noções de lateralidade, espaço, tempo e linguagem oral. Também aprendem a compartilhar materiais e brinquedos, a se perceber como sujeito, a externar suas emoções, além de desenvolver coordenação motora ampla e fina.

A Matemática na Educação Infantil vai além de aprender a contar em sequência, a conhecer formas geométricas; é também saber se localizar, se reconhecer em um espaço, aprender a resolver problemas cotidianos, formulando perguntas e buscando respostas.

A Modelagem Matemática na perspectiva de Burak (1992) vem se constituindo desde algum tempo em uma possibilidade para as práticas pedagógicas nesse nível de escolaridade. $\mathrm{A}$ prática acontece a partir de temas de interesse das crianças, não necessariamente matemáticos, buscando formar, contribuir nessa fase de modo a desenvolver pessoas críticas, capazes de buscar informações quando precisam, buscar independência, elaborando perguntas, formulando respostas.

A Modelagem Matemática na Educação Infantil, quando na perspectiva da Educação Matemática, sofre algumas adequações em suas etapas, pois por se tratar de crianças pequenas, precisa-se de uma maior mediação por parte do professor. Cabe então a ele, durante as conversas e brincadeiras, observar e perceber os interesses e gostos das crianças e sugerir ou auxiliar na escolha do tema, possibilitando às crianças deliberarem em aceitar ou não o tema. Este artigo consiste em um recorte de uma pesquisa de mestrado (BELO, 2016) e tem como objetivo descrever as contribuições da Modelagem Matemática no desenvolvimento das crianças em uma turma de Pré I, entre 4 a 5 anos.

O artigo está organizado em: Trajetória histórica da Educação Infantil no Brasil; as ideias matemáticas na Educação Infantil; Modelagem Matemática na Educação; Procedimentos metodológicos; Descrição, análise e discussões sobre as práticas com Modelagem Matemática; e Considerações.

\section{Trajetória histórica da Educação Infantil no Brasil}

No Brasil, conforme alguns autores, como Paschoal e Machado (2009) e Silveira e Sampaio (2010), até meados do século XIX o cuidado das crianças cabiam à família, pois apenas os homens trabalhavam fora, cabendo a eles o sustento da casa e às mulheres, cuidar dos filhos 
e a realização dos afazeres domésticos. Era no convívio familiar com adultos e outras crianças, que aprendiam sobre as tradições, as normas e regras da sua cultura.

Segundo Andrade (2010), em países da Europa o surgimento e a expansão das creches aconteceram devido ao recrutamento das mulheres como mão de obra para as fábricas, necessitando atendimento para seus filhos. Já no Brasil, as creches surgiram para tentar minimizar os problemas sociais das mulheres e crianças que estavam em estado de miséria.

Conforme Silveira e Sampaio (2010), o investimento na educação brasileira foi após a Proclamação da República, mas voltado para o ensino primário. A necessidade de atendimento às crianças surgiu com a chegadas das fábricas e mudanças na estrutura familiar, quando as mulheres começaram a trabalhar nas indústrias. No início, quem ficava com essas crianças eram mulheres que não trabalhavam, que se dispunham a tal, sendo de outras famílias ou seus parentes, como forma de caridade. "Posteriormente, a partir da organização de movimentos e sindicatos de operários(as), foi reivindicado inicialmente aos empresários e posteriormente ao governo instituições como creches e pré-escolas" (SILVEIRA e SAMPAIO, 2010, p. 30). Para Santos (2010),

no decorrer dos tempos, a história da Educação Infantil no Brasil teve diferentes mudanças na sua função, pois o papel das instituições visava apenas o cuidar, não havia a preocupação de educar as crianças de zero a cinco anos. Anteriormente, as instituições infantis somente atendiam às crianças socioeconomicamente desfavoráveis, por possuírem visão assistencialista, atualmente, passaram a ter 0 papel de educativa, ou seja, o cuidar e o educar fazem parte intrinsecamente da educação da criança, pois a educação é um direito da criança desde o seu nascimento (p. 7).

As instituições eram assistencialistas, criadas para atender as crianças pobres e não tinham cunho pedagógico como hoje. Esta visão assistencialista permaneceu por muito tempo no Brasil, "a primeira Constituição Federal, de 1824, e a primeira Lei Geral de Educação do país, de 15 de outubro de 1827, não previam o atendimento escolar infantil" (CUNHA e SILVA, 2019, p. 224).

Conforme Oliveira (2006, p. 4), foi após a Constituição de 1988, e finalmente com a LDB 9394/96 que a Educação Infantil "[...] passa a ser entendida como parte da Educação Básica, sendo um direito da criança e não só um direito da mãe trabalhadora. Ela adquiriu características importantes até mesmo com relação a formação do profissional que atua nesta área".

A Lei de Diretrizes e Bases da Educação Nacional de 1996 retifica ressaltando que a 
Educação é um direito de todas as crianças, a qual "define a Educação Infantil como primeira etapa da educação básica (Art. 29), demonstrando com isso a importância da Educação Infantil no desenvolvimento da criança" (SILVA, 2010, p. 31).

Segundo Oliveira (2006, p. 4), na Educação Infantil, o professor tem que ter clareza do seu papel e o da instituição na aprendizagem das crianças, pois ele deve

cuidar e educar as crianças, sem diferenciar estas ações, uma vez que nos momentos da alimentação e higiene, o professor está educando e quando está estimulando a leitura, está cuidando. Estas atuações (cuidar e educar) na Educação Infantil devem estar integradas para promover o desenvolvimento global da criança.

Em 2010, foi homologada as Diretrizes Curriculares Nacionais para a Educação Infantil (DCNEI), um documento que ressalta que as propostas pedagógicas da Educação Infantil devem ter como eixos norteadores as interações e brincadeiras e devem respeitar os seguintes princípios:

- Éticos: da autonomia, da responsabilidade, da solidariedade e do respeito ao bem comum, ao meio ambiente e às diferentes culturas, identidades e singularidades.

- Políticos: dos direitos de cidadania, do exercício da criticidade e do respeito à ordem democrática.

- Estéticos: da sensibilidade, da criatividade, da ludicidade e da liberdade de expressão nas diferentes manifestações artísticas e culturais (BRASIL, 2010, p. 16).

Depois de alguns anos de discussão, foi aprovado em 2017 a versão final da Base Nacional Comum Curricular (BNCC) que, assim como as DCNEI), apresenta as interações e brincadeiras como eixo que norteia a Educação Infantil, indicando, ainda, seis direitos de aprendizagens: conviver, brincar, participar, explorar, expressar-se, conhecer-se, e estruturando a organização curricular em cinco campos de experiências, com objetivos e direito de aprendizagens.

Após compreender um pouco da história e dos documentos que norteiam as práticas pedagógicas na Educação Infantil, na próxima seção abordaremos as ideias matemáticas neste nível de ensino.

\section{As ideias matemáticas na Educação Infantil}

As primeiras ideias matemáticas vão além de contagem e reconhecimento de números; elas compreendem também o saber se localizar em um espaço. Noções de esquerda, direita, 
frente, atrás, alto, baixo, em cima e embaixo, comandos como pare e siga, andar contornando obstáculos, favorecem o desenvolvimento da criança.

A Matemática na Educação Infantil, segundo Aragão (2010), "tem como finalidade proporcionar oportunidades para que as crianças desenvolvam a capacidade de estabelecer aproximações com algumas noções matemáticas presentes no seu cotidiano pela elaboração/construção do seu pensamento" (p. 20).

A Matemática, para Cerquetti-Aberkane e Berdonneau (1997), é proporcionar oportunidades para que a criança aja e reflita as suas ações, repense sobre os acontecimentos, antecipe e procure prever o que poderá acontecer, dando sentido e estruturando pouco a pouco os seus conhecimentos; ensinando e possibilitando que as crianças pensem e reflitam, auxilia na organização das ideias e desenvolvimento dos seus pensamentos, aprendendo a argumentar com exatidão.

Assim, pensar na Matemática na Educação Infantil, de acordo com Klein e Konrath (2019), é propiciar que a criança por meio do brincar e de expressar-se construa noções e conceitos matemáticos. É desenvolver o pensamento matemático, é favorecer as aprendizagens associadas à linguagem matemática, por meio de contagens, manipulando materiais, construindo com blocos, explorando os espaços internos e externos da escola.

Para Lorenzato (2011), o professor deve oferecer situações em que as crianças realizem experiências e descobertas, assim elas "poderão desenvolver suas habilidades na resolução de problemas, ser motivadas a fazer conjecturas e a apresentar suas justificativas verbais ou escritas" (p. 1). Ainda, ressalta a importância de o professor estimular as crianças a fazer perguntas, se comunicar entre si e trocar ideias. Mas, partindo dos conhecimentos que as crianças já possuem, proporcionando que apreciem a beleza matemática, descubram e desenvolvam novos conhecimentos matemáticos no cotidiano. Nesse sentido, "a criança aprende pela sua ação sobre onde vive: a ação das crianças sobre os objetos através dos sentidos é um meio necessário para que ela consiga realizar uma aprendizagem significativa" (LORENZATO, 2011, p. 11).

Assim, as crianças desde pequenas "devem estar envolvidas em atividades de coletar, organizar e descrever dados, pois durante a realização desse trabalho várias habilidades são desenvolvidas, como por exemplo: exploração, conjectura e comunicação" (SMOLE, 2000, p. 85).

$\mathrm{Na}$ Educação Infantil, as atividades de localização de forma tradicional não fazem com que as crianças sejam as responsáveis por "buscar uma solução; decidir, explicitamente ou não, 
"o que usar" para resolvê-las. Isso significa que são elas que determinam quais podem ser os conhecimentos que devem ser postos em prática; comprovar a solução encontrada" (SAIZ, 2006, p. 145),

Conforme Lorenzato (2011), devemos começar a trabalhar com as crianças, desde pequenas, noções como

grande/pequeno, maior/menor, grosso/fino, curto/comprido, alto/baixo, largo/estreito, perto/longe, leve/pesado, vazio/cheio, mais/menos, muito/pouco, igual/diferente, dentro/fora, começo/meio/fim, antes/agora/depois, cedo/tarde, dia/noite, ontem/hoje/amanhã, devagar/depressa, aberto/fechado, em cima/embaixo, direita/esquerda, primeiro/último/entre, na frente/atrás/ao lado, para frente/para trás/para o lado, para a direita/para a esquerda, para cima/para baixo, ganhar/perder, aumentar/diminuir (p. 24).

E ainda,

seja qual for a noção e o campo matemático (espaço, número, medida) que estiver sendo trabalhado, haverá sempre uma relação direta com um dos conceitos físicomatemáticos seguintes: tamanho, lugar, distância, forma, quantidade, número, capacidade, tempo, posição, medição, operação, direção, volume, comprimento, massa (LORENZATO, 2011, p. 25).

Também, "o conceito de medida é abrangente, pois pode se referir a distância, superfície, espaço, massa, calor (temperatura), movimento (velocidade) e duração (tempo)" (LORENZATO, 2011, p. 53). Todos esses conceitos matemáticos, e outros que são essenciais para 0 desenvolvimento integral da criança, devem partir das ações nas interações e brincadeiras.

\section{Modelagem Matemática na Educação}

A Modelagem Matemática na Educação Matemática tem diferentes abordagens e concepções pedagógicas sob pontos de vistas distintos. Apresentamos algumas concepções, como as de Barbosa (2004), Caldeira (2009), Burak (1992, 2010), Almeida, Silva e Vertuan (2012).

A Modelagem Matemática, para Barbosa (2004, p. 75), "é um ambiente de aprendizagem no qual os alunos são convidados a problematizar e investigar, por meio da matemática, situações com referência na realidade". Em sua concepção, Caldeira (2009, p. 38), vê a Modelagem Matemática não só como um método de ensino-aprendizagem, mas também como 
advindas das interações sociais, levando em consideração, também, aspectos da cultura matemática não escolar. Deverá fazer com que o estudante perceba a necessidade do enfrentamento da sua realidade, lutar contra ela se necessário for; romper com determinadas amarras e com as adaptações a que comumente estão acostumados a lidar. Esse enfrentamento vai se dar não somente pela nova racionalidade, mas também e, principalmente, pela sua participação ativa em sala de aula. Problematizar, elaborar suas próprias perguntas, desenvolver por meio da pesquisa, refletir e tirar suas próprias conclusões - pressupostos básicos dessa perspectiva de Modelagem Matemática.

Para Almeida, Silva e Vertuan (2012),

uma atividade de Modelagem Matemática tem em uma situação problemática a sua origem e tem como característica essencial a possibilidade de abarcar a cotidianidade ou a relação com aspectos externos à Matemática, caracterizando-se como um conjunto de procedimentos mediante o qual se definem estratégias de ação do sujeito em relação a um problema (p. 15).

A Modelagem Matemática, segundo a concepção de Burak (1992, p. 62), "constitui-se em um conjunto de procedimentos cujo objetivo é construir um paralelo para tentar explicar matematicamente os fenômenos presentes no cotidiano do ser humano, ajudando a fazer predições e tomar decisões".

Segundo Kaviatkovski e Burak (2011, p. 12), como metodologia de ensino e aprendizagem, a Modelagem Matemática nos Anos Iniciais do Ensino Fundamental "possibilita ao estudante perceber que ele está inserido em um mundo no qual interage permanentemente e é por meio dessa interação que a Matemática se constitui e adquire significado".

A concepção adotada neste artigo é a de Burak (1992, 2004, 2010, 2019). Consideramos que sua concepção possibilita, por meio dos fundamentos teóricos e epistemológicos, que a criança "desenvolva a autonomia, que seja: crítico, capaz de trabalhar em grupo, tomar decisões diante das situações do cotidiano, da sua vida familiar, profissional, ou de sua condição de cidadão" (BURAK, 2010, p. 17).

Na Educação Infantil e nos Anos Iniciais do Ensino Fundamental, essa prática pedagógica pode se apresentar a partir de atividades lúdicas, como brincadeiras, músicas, histórias infantis, jogos e outras de interesse das crianças. Segundo Burak (2004), o processo de Modelagem Matemática parte de dois princípios: 1) temas de interesse do(s) grupo(s) de participantes e 2) obtenção de dados, sempre que possível, no local onde se dá o interesse do grupo ou dos grupos.

Na concepção de Burak (2010), são sugeridas cinco etapas para o desenvolvimento de práticas com Modelagem Matemática: escolha do tema; pesquisa exploratória; levantamento dos 
problemas; resolução dos problemas; e análise críticas das soluções, etapas essas que podem sofrer alterações conforme a faixa etária dos estudantes. Conforme Belo (2016),

1. Escolha do Tema: está sempre vinculada ao interesse dos estudantes, neste estudo, ao interesse das crianças ou dos grupos de crianças, partindo das observações da professora em relação aos gostos e interesses das crianças, e da copartipação nas escolhas e decisões sobre o tema.

2. Pesquisa Exploratória: é a etapa em que o(s) grupo(s) busca(m) conhecer mais sobre o assunto escolhido. Devido a faixa etária, esta etapa pode contar com a ajuda da professora e dos pais ou responsáveis.

3. Levantamento do(s) problema(s): uma etapa importante onde os estudantes, no nosso caso, as crianças, nesta fase do ensino, sob a mediação do professor, vão discutir os dados coletados e levantar as questões que consideram importantes de serem respondidas.

4. Resolução do(s) problema(s) e o trabalho com os conteúdos no contexto do tema: é a etapa em que os estudantes (crianças) utilizam ou constroem os conceitos e o conhecimento matemático, entre outros, capazes de fornecer respostas às questões levantadas.

5. Análise crítica das soluções: as soluções encontradas durante a resolução dos problemas ganham uma dimensão importante. É um momento para refletir sobre o significado da solução, sob o ponto de vista matemático, social, cultural, ambiental, econômico ou outro.

Em relação à Educação Infantil e aos Anos Iniciais,

deve primar por favorecer a formação das ideias e conceitos matemáticos. Esse é um momento escolar em que se deve privilegiar a construção do conhecimento matemático e para isso a utilização da linguagem é fundamental, pois ainda a forma simbólica está sendo construída na estrutura cognitiva dos estudantes desta fase de ensino. Assim, muitas atividades envolvendo a Modelagem podem ensejar as ideias de lateralidade, formas, ideias de sequências, ideia de padrões, a formação do conceito de número, ideias de classificação e ordenação. (BURAK, 2014, p. 5)

A Modelagem Matemática na Educação Infantil possibilita que as aulas sejam dinâmicas, de interesse das crianças e que elas aprendam a formular perguntas e respostas, a se relacionar e respeitar os outros, e a se desenvolver de forma integral - afetiva, cognitiva, social e física. 


\section{Procedimentos metodológicos}

Este artigo é o relato de como ocorreram as práticas com Modelagem Matemática em uma turma de Pré I, com dez crianças de 4 a 5 anos, em uma escola pública no Município de Irati (PR).

A pesquisa foi uma investigação qualitativa, na modalidade de estudo de caso, que "consiste no estudo profundo e exaustivo de um ou poucos objetos, de maneira que permita seu amplo e detalhado conhecimento" (GIL, 2002, p. 54). Segundo Lüdke e André (1986), o estudo de caso visa à descoberta, enfatiza a "interpretação em contexto" (p. 18), busca "retratar a realidade de forma completa e profunda" (p. 19), usa "uma variedade de fontes de informação" (p. 19) e tem como finalidade "retratar uma unidade em ação" (p. 22).

Desenvolvida em uma turma de Educação Infantil, cujas crianças não possuem o domínio da escrita, foram coletados dados por meio de observações, conversas com/e entre elas, fotos e filmagens, e análises da aprendizagem das crianças a partir de práticas com a Modelagem Matemática. Foram desenvolvidas práticas com Modelagem Matemática, porém aqui serão relatados somente os procedimentos iniciais do desenvolvimento destas.

Primeiramente, foram observados os gostos e interesses das crianças durante duas aulas e, também, durante conversas com a professora regente. Em seguida, foi organizada uma roda de conversa e dentre alguns dos comentários das crianças, surgiu o interesse pelo tema brincadeiras antigas. $O$ tema foi aceito por todos, levado pela curiosidade de saber como os pais brincavam. Houve uma conversa com as crianças e foi solicitado que perguntassem aos pais e avós com que brincavam quando crianças. Pensando na faixa etária das crianças e na possível dificuldade de pais e filhos em compreender a proposta, foi elaborado um questionário para ser respondido, conforme Quadro 1.

\section{Quadro 1: Questionário enviado aos pais das crianças}

Senhores Pais, estamos trabalhando sobre brincadeiras antigas. Favor contar para o seu filho (a), e responder abaixo:

1. Comparando com a facilidade de se ter brinquedos hoje em dia, ao contrário de antigamente, quando era pequeno, do que vocês gostavam de brincar?

2. Quais brincadeiras e cantigas de roda costumavam brincar e cantar?

3. Na infância de seus pais (avôs), como eram os brinquedos? Do que eles costumavam brincar? 
A maioria dos pais respondeu ao bilhete, tendo de forma geral as seguintes respostas:

Na pergunta 1, houve diversas respostas como: pular amarelinha, carrinho de rolimã, pular elástico, pular corda, esconde-esconde, bambolê, perna de pau, pula saco, jogar bola, bola de gude, bete ombro, piquenique, cobra cega, pega-pega, queimada, boneca, xadrez, escolinha, casinha.

Na pergunta 2, as respostas foram: marcha soldado, ciranda-cirandinha, Terezinha de Jesus, roda cutia, atirei o pau no gato, sapo cururu, o barquinho virou, vaca amarela, pirulito que bate-bate, lenço atrás.

Na pergunta 3, os avós brincavam de: jogar peteca, jogar bola, carrinhos de rolimã, bonecas de pano, de casinha, balanço no cipó, boneca de sabugo de milho, amarelinha, bolinha de gude, bolo de barro, gaióta, bolas de meia, pião, pular corda.

Os nomes das brincadeiras foram surgindo a partir do diálogo com as crianças. Elas aceitavam ou não desenvolver determinadas brincadeiras, sugeriam e até ensinavam algumas para a pesquisadora. Durante o relato das crianças sobre a infância dos tios ou primos, surgiram outras brincadeiras das quais houve aceitação em brincar ou não. E neste relato será apresentado como aconteceu a escolha e o desenvolvimento de duas práticas com Modelagem Matemática no contexto do tema Brincadeiras Antigas.

A coleta dos dados se deu pelas observações, conversas com as crianças, fotos e filmagens, e a análise da aprendizagem das crianças, foram realizadas com base nas falas e diálogo entre as crianças, e entre as crianças e a pesquisadora a partir das práticas com a Modelagem Matemática.

\section{Descrições das práticas com Modelagem Matemática}

Como mencionado anteriormente, este artigo é um recorte da pesquisa de mestrado (BELO, 2016), na qual foi relatado o desenvolvimento do projeto com o tema "Brincadeiras Antigas". A dissertação contempla 19 brincadeiras, mas este relato será feito abordando 0 processo de escolha e desenvolvimento de apenas duas delas, para cumprir com o objetivo deste artigo. Para a definição das atividades relatamos alguns dos diálogos entre as crianças e a pesquisadora.

Pesquisadora: Lembram que a professora perguntou para vocês do que 
seus pais brincavam?

Criança 1: Meu pai gostava de dirigir!

Pesquisadora: Dirigir o que?

Criança 1: Carrinho.

Criança 2: Minha mãe gostava de brincar de boneca de pano e meu vô de cavalinho de pau.

Muitas crianças falavam juntas repetindo o que os colegas diziam. Então, para haver uma organização, a pesquisadora pegou os questionários e deu início aos comentários das respostas:

Pesquisadora: A mãe do M.... escreveu aqui que ela brincava de cobra cega. Ela te explicou como brincava?

A criança não sabia responder. Então outra criança disse:

Criança 3: A gente pega um pano e coloca (fala apontando para o rosto)

Pesquisadora: Vocês querem brincar de cobra cega?

Crianças: Simmmm!

Como houve unanimidade na resposta, a brincadeira teve início.

Pesquisadora: Então eu vou emprestar uma blusa para vendar! Quem quer começar?

Criança3: Euuuuu!

A criança que se prontificou a começar, era aquela que havia explicado como era a brincadeira.

Na brincadeira cobra cega, a criança, com os olhos vendados, precisa, por meio do toque, perceber as características de quem está tocando, ou seja, se tem o cabelo curto ou comprido, se ele está preso ou solto, e fazer comparações a partir do que já conhece dos colegas, adivinhar quem é etc. Essa brincadeira faz com que a criança perceba que cada um tem uma característica que o define. Para realizar a brincadeira, a criança que fará o papel da cobra cega pode ser escolhida pelos demais ou se oferecer para tal. Nessa investigação, a criança 3, que mostrou conhecer a brincadeira, conforme já citado no diálogo acima, se prontificou em fazer o papel da cobra cega, fato aprovado pelas demais crianças. Assim, iniciou-se a brincadeira. 
As crianças permanecem em roda, pois já estavam dessa forma devido à roda de conversa para a escolha da brincadeira. Os olhos da criança que seria a cobra cega foram vendados. As demais crianças foram orientadas a trocar de lugar de forma silenciosa para que a criança não as reconhecesse pela voz, que não é o objetivo desta brincadeira. Depois de todos estarem em seus novos lugares, ainda em roda, a cobra cega iria até uma criança e, por meio do toque, precisaria descobrir que criança é, tendo três chances para acertar. Nesse momento, todas elas foram orientadas a ficar em silêncio, principalmente a que estava sendo tocada para não ser identificada pela voz. Se a cobra cega acertasse o nome da pessoa que está tocando, a criança tocada passaria a ser cobra cega e assim sucessivamente. Se não acertasse com as três chances, a venda seria retirada para que a criança que a utilizava pudesse saber quem estava tocando. $A$ venda seria colocada novamente na criança e as demais trocariam de lugar, repetindo a brincadeira. Caso a criança que errou não queira continuar como cobra cega, aquela que foi tocada é convidada a sê-la. Se esta aceitar, seus olhos são vendados. Se não, pede se outro voluntário e a brincadeira continua.

Para manter sigilo dos nomes quando elas são chamadas, colocamos somente uma inicial, não sendo necessariamente a do nome da criança.

Pesquisadora: M........, a professora vai te ajudar a chegar perto de uma criança, você vai encostar nela e tentar adivinhar quem é. Lembrando que elas não podem falar porque a cobra cega precisa descobrir o nome de quem ela está tocando.

Com ajuda da professora, a criança foi até um dos colegas e o tocou para tentar descobrir quem era.

Pesquisadora: Quem é?

A criança tocou por um tempo, pensou e disse: É o N.....

Pesquisadora: Isso, muito bem! Agora é a vez dele ser a cobra cega.

Depois de colocar a venda, as crianças, em silêncio, trocaram de lugar na roda e, com ajuda da pesquisadora, a criança que era a cobra cega, chegou até um colega.

Pesquisadora: Quem é?

A criança tocou e disse: é a M.... 
Pesquisadora: Não, mais uma vez!

Criança: é a S...

Pesquisadora: Isso! Agora é vez da S... ser a cobra cega.

E assim a brincadeira continuou até todas as crianças participarem. Tomava-se o cuidado de conduzir as crianças até aquelas que não tinham participado ainda.

Ainda em roda, deu-se continuidade a conversa e a leitura das respostas do questionário preenchido pelos pais. Outra brincadeira de que os pais brincavam era chamada lenço atrás. Porém, ao serem convidadas para brincar, as crianças não aceitaram e sugeriram outra brincadeira chamada pato-pato-ganso. A pesquisadora não conhecia tal brincadeira, então uma criança se dispôs a ensiná-la. O fato pode ser verificado no diálogo a seguir.

Pesquisadora: Agora, outra brincadeira de que os pais brincavam era lenço atrás ou bola atrás. Vocês sabem como se brinca? Vocês já brincaram?

Crianças: Sim!

Criança 4: Vamos brincar de pato-pato-ganso?

Pesquisadora: Eu não sei como se brinca.

Criança 4: Assim! (se levantou para mostrar como fazia). Tem que ir falando pato, pato, pato (tocando na cabeça da criança) e quando tocar e falar ganso, a criança tem que correr atrás da outra.

Pesquisadora: Ah, sim. Todos querem brincar de pato-pato-ganso?

Crianças: Sim!

Todas as crianças concordaram em brincar de pato-pato-ganso ao invés de lenço atrás. Assim, a pesquisadora, a qual participou da brincadeira, juntamente com as crianças organizaram a roda, e a criança que sugeriu e explicou como se brincava começou fazendo o papel de ganso.

Criança 4: (Tocando na cabeça de cada criança) Pato, pato, ganso.

Então a criança tocada como ganso, levantou e saiu correndo tentar pegar a criança 4. Para não ser pega, ela fazia estratégias como correr e parar e trocar de direção na roda, até conseguir se sentar no lugar que a criança estava. 
Como a criança não conseguiu pegar a colega antes de se sentar, ela passou a ser 0 ganso e a falar pato-pato-ganso.

Criança 5: Pato, pato, pato, pato, pato, pato, pato, pato, pato, ganso.

E assim, a criança que era tocada como ganso tentava pegar a outra que a tocou e esta tinha que se sentar no lugar antes de ser pega. E assim a brincadeira continuou.

Durante a brincadeira as crianças torciam e falavam:

- Corre, corre!

- Olhe aqui o lugar dela!

— Vai! Vai! (Torcendo e batendo palmas)

- Ele não foi ainda!

— Eu também não fui!

Todas as crianças foram envolvidas inclusive a pesquisadora que estava junto na roda. Em um momento da brincadeira, a criança, que foi nomeada como ganso, conseguiu pegar a colega antes que ela sentasse no lugar.

Pesquisadora: $E$ agora o que acontece?

Crianças: Ele tem que se sentar no meio da roda até acabar a brincadeira!

E assim ele sentou e a brincadeira continuou com a criança que havia pego o colega. A brincadeira terminou depois que todos já haviam participado várias vezes. Todos disseram estar cansados e decidiram parar.

\section{Discussões e resultados}

Conforme relatado aqui, as brincadeiras foram sendo desenvolvidas conforme os diálogos com as crianças aconteciam. E para que isto acontecesse, rodas de conversa eram feitas onde as crianças contavam o que os pais e avós haviam contado sobre suas brincadeiras. A pesquisadora lia as repostas de cada um e, em conjunto, decidiam pela realização ou não da brincadeira. Durante os diálogos, foi possível perceber o envolvimento tanto das crianças quanto dos pais por meio dos detalhes que as crianças repassavam sobre as brincadeiras, sabendo até explicar como 
era cada uma delas, sem precisar a pesquisadora ler o que os pais haviam escrito.

A roda de conversa, conforme Reame et al. (2012), é o momento de interação do grupo, podendo se olhar; trocar informações; comunicar e expressar suas ideias, sentimentos e compreender as ideias e os sentimentos do outro. Ainda segundo as autoras, a utilização da roda para organizar as atividades a serem realizadas durante o dia possibilita que as crianças apresentem intenções, negociem a distribuição e a ordem das atividades, tomem decisões. Assim, "a roda assume a função essencial de desenvolvimento da autonomia e da liberdade com responsabilidade" (REAME et al., 2012, p. 20).

Para a realização da brincadeira, as crianças já estavam em roda, pois é assim que dialogavam e decidiam do que iriam brincar. Então uma criança foi escolhida para ser a cobracega e iniciar. Ela teve os olhos vendados com uma blusa. A cabra-cega foi até uma criança e, por meio do toque, teve que acertar quem era, como já explicado acima.

Esta brincadeira de cobra cega também ajudou a desenvolver a memória visual que "é a habilidade de lembrar-se daquilo que não está mais sob sua vista" (LORENZATO, 2011, p. 47). Isso acontecia quando as crianças, a partir do tato, precisavam associar as características percebidas com o que haviam visto anteriormente para descobrir em qual criança estavam tocando. Elas precisavam sentir, perceber e lembrar quem tinha determinado comprimento de cabelo, características das roupas, as quais elas haviam visto antes de serem vendadas.

Durante a brincadeira, as crianças ficavam em total silêncio, tomando cuidado para não serem reconhecidas enquanto o colega vendado se dirigia até elas. Porém, algumas vezes, os colegas do lado acabavam dizendo quem era o colega ao lado. Quando isso acontecia, a brincadeira era repetida com aquele que estava vendado.

Smole (2000), entende que "a criança vive inserida num contexto social que se encarrega de emitir a ela muitas informações que, em sua maioria, são geradas e percebidas pela criança, enquanto explora o espaço ao seu redor" (p. 105). Nesse sentido, a brincadeira corrobora com a afirmação da autora quando expressa que "ao brincar, a criança pensa, reflete e organiza-se internamente para aprender aquilo que ela quer, precisa, necessita e que está no momento de aprender" (SMOLE, 2000, p.123).

Após todas as crianças brincarem e, por decisão de trocar de brincadeira, voltamos ao questionário. Os pais haviam contado que brincavam de lenço atrás. Uma brincadeira de roda onde uma criança é escolhida para deixar o lenço atrás da outra e correr para não ter seu lugar 
pego por esta.

Porém, as crianças não quiseram esta brincadeira e, como a Modelagem Matemática na concepção assumida considera que a criança escolha algo do seu interesse, elas optaram por outra brincadeira, como aconteceu na escolha da brincadeira pato-pato-ganso.

As crianças corriam e usavam táticas para fugir do colega, como voltar, parar, fazer de conta que vai e não vai e corriam para se sentar no lugar da outra. Quando a criança faz de conta que corre e não corre, ela utiliza uma estratégia que envolve uma ação cognitiva, ou seja, pensar, realizar e avaliar a ação. Para isso, foram envolvidas a coordenação motora e a psicomotricidade, sendo a segunda aquela que define o homem como objeto de estudo "através do seu corpo em movimento, no tocante ao seu mundo interno e externo. Está relacionada, dentre outras definições, ao processo de maturação, onde o corpo se torna a origem das aquisições cognitivas, afetivas e orgânicas" (ARANHA, 2016, p.14), envolvendo "toda ação realizada pelo indivíduo; é a integração entre o psiquismo e a motricidade, buscando um desenvolvimento global, focando os aspectos afetivos, motores e cognitivos, levando o indivíduo à tomada de consciência do seu corpo por meio do movimento" (ARAÚJO e SILVA, 2013).

Observou-se que as crianças tinham o cuidado de envolver os demais colegas na brincadeira, inclusive a pesquisadora que estava sentada na roda para aprender como era. Segundo Kamii (2008), as crianças entre quatro e cinco anos possuem dificuldade em envolver todos nas brincadeiras e não tem essa preocupação, ao contrário das mais velhas que tomam esse cuidado e, se esquecem alguém, reparam o erro, voltando e incluindo este na brincadeira.

Porém, o que percebemos nessa turma de crianças de quatro a cinco anos, onde foi realizada esta investigação, é que existia a preocupação em envolver os demais colegas na brincadeira, inclusive a pesquisadora. O diálogo entre as crianças era: Vai corre; Sente aqui; Agora você é o ganso; Ela não foi ainda; Eu não fui ainda. Elas riam, torciam, batiam palmas chamando a criança pelo nome e incentivando a mesma a correr para que não fosse pega e pudesse se sentar no lugar da outra. Esperavam sua vez, atentas ao colega que era o "ganso" para ouvir o que estava falando, pois, somente a criança que fosse o ganso podia sair e correr para tentar pegar o colega. Esse tipo de atividade também desenvolve na criança a autonomia que é adquirida por meio da confiança em si mesma, percebendo que é capaz.

Segundo Piaget (1948) apud Kamii (2008), a finalidade da educação "deve ser a de desenvolver a autonomia da criança, que é indissociavelmente social, moral e intelectual" (p. 33). 
Estas brincadeiras e outras da proposta com práticas de Modelagem Matemática, lembrando que este é apenas uma parte do que foi desenvolvido nesta turma, possibilitou à criança tomada de decisões pelo fato de estar à frente da realização das brincadeiras, promovendo interação e diálogo enquanto orientava a pesquisadora e os colegas.

Faz parte da Modelagem Matemática permitir que a criança aceite ou não participar de uma brincadeira possibilitando desenvolver nela conceitos não só matemáticos. Ao propor a brincadeira lenço atrás, citada no questionário enviado aos pais e a fala da criança - Vamos brincar de pato-pato-ganso? - a qual foi aceita pelas demais, faz com que elas se sintam motivadas e importantes nas realizações das práticas pedagógicas. Suas ideias são levadas em consideração e aceitas para o início de uma prática com Modelagem, podendo dar suas opiniões e sugestões e, também, tendo a oportunidade de ensinar as outras, como aconteceu com esta brincadeira que a pesquisadora não conhecia. Elas também aprendem a respeitar a opinião dos colegas, esperar sua vez e ouvir quando alguém estava falando. A pesquisadora não conhecia a brincadeira pato-pato-ganso. Foi uma criança que a ensinou e organizou tudo. Elas mostravam preocupação com os colegas, como: Ela não foi ainda! Agora você é o ganso!

Essa brincadeira também estimulou o processo cognitivo, pois possibilitou às crianças pensar, usar a criatividade e elaborar estratégias para fugir, exercitando o raciocínio espacial ao tentar descobrir o caminho mais curto para chegar no lugar para não ser pego. Houve afetividade e cooperação entre as crianças, pois elas mostravam ao colega o seu lugar e torciam por ele. Nesse sentido, "quando brinca, a criança assimila o mundo à sua maneira, sem compromisso com a realidade, pois sua interação com o objeto não depende da natureza do mesmo, mas da função que a criança lhe atribui" (PIAGET, 1971 apud BOMTEMPO, 2011, p. 66).

Estas duas brincadeiras relatadas, cobra cega e pato-pato-ganso, favoreceram a iniciativa, autonomia, autoconfiança, o desenvolvimento das noções frente/atrás, espaço, distância na roda e de um lugar até o outro, assim como a velocidade para correr e não ser pego. Houve o desenvolvimento da linguagem oral por meio do diálogo no momento de escolhas e, durante as brincadeiras, a percepção tátil ao tentar conhecer o colega pelas características físicas a partir do toque e memória visual, associando o que estava tocando com o que havia percebido anteriormente. Uma cultura de respeito, incentivo, torcida e apoio também foi desenvolvida entre eles.

Nessas atividades, percebemos o desenvolvimento integral da criança, ações intencionais 
(afetividade) enquanto ajudavam, torciam pelos colegas. A construção de representações mentais (cognitivo) ao tentar perceber que eram os colegas que estavam tocando (cobra cega) e ao criar táticas para fugir ou pegar seus colegas (pato-pato-ganso), a coordenação motora (físico), ao correr, ao tocar os colegas e as trocas nas interações entre eles durante as atividades (social).

A Modelagem Matemática, quando utilizada como prática pedagógica na Educação Infantil, deve passar por ajustes, pois devemos levar em conta a faixa etária e a ausência de leitura e escrita. Dessa forma, as etapas propostas por Burak (2010) sofrem algumas modificações, mas sem perder a essência da proposta, mantendo seus princípios, partindo do interesse do grupo ou dos grupos e possibilitando a coleta de dados, sempre que possível, no ambiente onde se localiza o interesse dos participantes, ainda que com adequações.

Nessa investigação, a escolha dos temas desenvolvidos partiu das discussões e trocas de ideias entre as crianças, a pesquisadora e a professora-regente, das observações e diálogos entre os participantes. Coube à pesquisadora perceber os gostos, o interesse e o que mais chamava a atenção das crianças. Em todos os momentos houve troca de ideias e aceitação ou não da realização da brincadeira pelo grupo.

A pesquisa exploratória na Educação Infantil partiu das crianças e da professora/pesquisadora que forneceu parte das informações e promoveu a troca de ideias com as crianças. Houve a oportunidade das mesmas e seus pais se manifestarem, como foi o caso do tema brincadeiras antigas, em que os pais conversaram com seus filhos, ensinaram as brincadeiras e responderam o questionário.

O levantamento de problemas nessa investigação foi constituído pelos conceitos matemáticos ou outros tipos de noções, previstos nas diretrizes para essa fase de escolarização. Nas duas brincadeiras relatadas, desenvolveu-se as noções de frente/atrás, espaço, distância, velocidade, coordenação motora, memória visual, percepção tátil, autoconfiança, afetividade, autonomia, interação, solidariedade e linguagem oral.

A resolução dos problemas nessa investigação relaciona-se ao desenvolvimento das práticas pedagógicas a partir dos temas escolhidos, neste caso, as brincadeiras. Na primeira brincadeira relatada, os participantes tinham que resolver o seguinte problema: pegar as crianças e não ser pego por elas. Na segunda, o problema era utilizar a parte sensória para identificar a outra criança.

A análise crítica das soluções nessa faixa etária se constituiu nas discussões em relação 
ao desenvolvimento das práticas, a percepção de conceitos envolvidos como noções de frente/atrás, espaço, distância, velocidade (para correr e não ser pego), linguagem oral, percepção tátil e auditiva (ao tocar ou ouvir a voz do colega). Para aumentar o potencial educativo dessa etapa, a utilização das tecnologias foi considerada fundamental, pois ofereceu a oportunidade de, por meio de filmagens, vídeos e outras formas, captar os movimentos, as manifestações orais e as expressões das crianças.

A Modelagem Matemática possibilita às crianças buscarem as ações, decidir como realizar a atividade, perceber seus acertos e erros, fazer sugestões e expressar seus sentimentos. Com isso, elas aprendem conceitos não somente matemáticos, mas a escutar e aceitar a opinião do outro, dar a sua opinião e entender que vivem em um grupo.

Segundo Kamii (2008, p. 62), é importante que a criança troque ideias, seja corrigida e corrija a outra, aprendendo assim por meio da interação com o outro, uma vez que "a confrontação social entre colegas é indispensável para o desenvolvimento do conhecimento lógico-matemático".

\section{Considerações}

A utilização da Modelagem Matemática como prática pedagógica vai além dos conhecimentos matemáticos, como se mostra nesse texto e possibilita também a interdisciplinaridade que acontece na Educação Infantil. Essa é a única etapa de ensino em que os conteúdos não são divididos por disciplinas ou áreas, podendo-se perceber a interação e socialização entre as crianças nas brincadeiras que envolvem o movimento. Nestas práticas, houve também a retomada histórica, pois se trata de brincadeiras que pais e avós brincavam.

Modificações nas etapas acontecem conforme a idade das crianças, como aconteceu na escolha do tema que partiu de observações da pesquisadora, conversas com as crianças e com a pesquisa exploratória em que as crianças tiveram auxílio dos pais e da pesquisadora para colherem informações. Porém, deixamos claro que não existe um "modelo" e que este é um relato das experiências de como a pesquisadora procedeu na realização das práticas pedagógicas. As modificações ocorrem dependendo da idade e do perfil das crianças. As maiores têm maior capacidade de opinar e ir atrás do que querem e precisam. Já as menores precisam da mediação da professora nas sugestões e encaminhamentos. 0 professor que se propõe a trabalhar com a Modelagem Matemática precisa estar preparado e disposto a aceitar as propostas das crianças e saber lidar com mudanças no decorrer do processo, pois as crianças podem modificar 0 
andamento das práticas. Dessa forma, elas acabam sendo protagonistas do seu conhecimento, como ocorreu na brincadeira pato-pato-ganso a qual as crianças escolheram brincar ao invés de lenço atrás citada na pesquisa pelos pais.

. A Modelagem Matemática parte do interesse das crianças, e quando é algo que as instiga, estas são incentivadas a buscar, conhecer, aprender, compreender e entender. As atividades podem ser desenvolvidas em pequenos grupos, favorecendo a interação entre os participantes.

Utilizar a Modelagem Matemática como prática pedagógica, já que ela sempre parte do interesse dos participantes, desenvolve 0 aspecto afetivo, potencializa a aprendizagem pelo diálogo e a interação entre todos.

A Modelagem Matemática na Educação Infantil possibilita trabalhar diversos conceitos matemáticos, além de desenvolver a socialização entre as crianças, o desenvolvimento da linguagem oral, na ampliação do vocabulário e da coordenação motora ampla. Os aspectos contidos nas propostas pedagógicas das Diretrizes Curriculares Nacionais da Educação Infantil (DCNEI) promovem um enriquecimento na formação e desenvolvimento da criança.

Esta pesquisa é um recorte das investigações sobre a Modelagem Matemática na Educação Infantil, novas experiências estão sendo realizadas para a compreensão em relação às contribuições da Modelagem Matemática nessa fase da Educação Básica.

\section{Referências}

ALMEIDA, Lourdes Werle de; SILVA, Karina Pessôa; VERTUAN, Rodolfo Eduardo. Modelagem Matemática na Educação Básica. São Paulo: Contexto, 2012.

ANDRADE, Lucimary Bernabé Pedrosa de. Educação infantil: discurso, legislação e práticas institucionais. São Paulo: EdUNESP; São Paulo: Cultura Acadêmica, 2010.

ARAGÃO, Rosália Maria Ribeiro de. Rumo à educação do século XXI: para superar os descompassos do ensino nos anos iniciais de escolar idade. In: BURAK, Dionísio; PACHECO, Edilson Roberto; KLÜBER, Tiago Emanuel. (Org). Educação Matemática: reflexões e ações. Curitiba: CRV, 2010, p. 11-25.

ARANHA, Mauricleide Leandro. A importância da ludicidade e da psicomotricidade para a Educação Infantil. 2016. Trabalho de Conclusão de Curso (Licenciatura em Pedagogia) - Centro de Educação. Universidade Federal da Paraíba. João Pessoa.

ARAÚJO, Andreza Santiago Gottgtroy de; SILVA, Eduardo Rodrigues da. As contribuições da 
psicomotricidade na educação infantil. 2013. Disponível em: http://www.educacaopublica.rj.gov.br/biblioteca/comportamento/0116.html.

BARBOSA, Jonei Cerqueira. Modelagem Matemática: O que é? Por quê? Como? Veritati, n. 4, p. 73-80, 2004.

BELO, Cibelli Batista. Modelagem matemática na educação infantil: contribuições para a formação da criança. 2016. 110f. Dissertação (Mestrado em Ensino de Ciências Naturais e Matemática) Setor de Ciências Exatas e de Tecnologia. Universidade Estadual do Centro-Oeste. Guarapuava.

BOMTEMPO. Edda. A brincadeira de faz de conta: lugar do simbolismo, da representação, do imaginário. In: KISHIMOTO, Tizuko Morchida. (Org.). Jogo, brinquedo, brincadeira e a educação. 14. ed. São Paulo: Cortez, 2011, p. 63-79.

BRASIL. Ministério da Educação. Secretaria de Educação Básica. Base Nacional Comum Curricular. Educação Infantil e Ensino Fundamental. Brasília: MEC/SEB, 2017.

BRASIL. Ministério da Educação. Secretaria de Educação Básica. Diretrizes Curriculares Nacionais para a Educação Infantil. Brasília: MEC/SEB, 2010.

BURAK, Dionísio. A Modelagem Matemática na perspectiva da Educação Matemática: olhares múltiplos e complexos. Educação Matemática Sem Fronteiras, Chapecó, v. 1, n. 1, p. 96-111, jan./jun. 2019.

BURAK, Dionísio. Modelagem Matemática e a sala de aula. In: I ENCONTRO PARANAENSE DE MODELAGEM EM EDUCAÇÃO MATEMÁTICA, 2004, Londrina. Anais do I EPREM. Londrina: UEL, 2004, p. 1-10.

BURAK, Dionísio. Modelagem Matemática nos diferentes níveis de ensino: uma perspectiva. In: XII ENCONTRO PARANAENSE DE EDUCAÇÃO MATEMÁTICA, 2014, Campo Mourão. Anais do XII EPREM. Campo Mourão: UNESPAR, 2014, p. 1-14.

BURAK, Dionísio. Modelagem Matemática sob um olhar de Educação Matemática e suas implicações para a construção do conhecimento matemático em sala de aula. Revista de Modelagem na Educação Matemática, Blumenau, v. 1, n. 1, p. 10-27, 2010.

BURAK, Dionísio. Modelagem Matemática: ações e interações no processo de ensinoaprendizagem. 1992. 460f. Tese (Doutorado em Educação) - Faculdade de Educação. Universidade Estadual de Campinas. Campinas.

CALDEIRA, Ademir Donizeti. Modelagem Matemática: um outro olhar. Alexandria, Florianópolis, v. 2, n. 2, p. 33-54, maio/ago. 2009.

CERQUETTI-ABERKANE, Françoise; BERDONNEAU, Catherine. O ensino da Matemática na Educação Infantil. Tradução de Eunice Gruman. Porto Alegre: Artes Médicas, 1997.

CUNHA, Myrtes Dias da; SILVA, Cecilia Resende. Reflexões acerca da estrutura curricular para a Educação Infantil. Ensino em Re-Vista, Uberlândia, v. 26, n.1, p.223-243, jan./abr. 2019.

GIL, Antonio Carlos. Como elaborar projetos de pesquisa. 4. ed. São Paulo: Atlas, 2002. 
HORN, Maria da Graça Souza. Brincar e interagir nos espaços da escola infantil. Porto Alegre: Penso, 2017.

KAMII, Constance. A criança e o número. Tradução de Regina de Assis. 36. ed. Campinas, São Paulo: Papirus, 2008.

KAVIATKOVSKI, Marinês Avila de Chaves; BURAK, Dionísio. O ensino e aprendizagem de Matemática nos Anos Iniciais do Ensino Fundamental à luz da Modelagem Matemática. In: SEMINÁRIO DE PESQUISA DO PPE, 2011, Maringá. Anais... Maringá: UEM, 2011, p. 1-18.

KLEIN, Delci Heinle; KONRATH, Raquel Dilly. A Matemática e os campos de experiências da Educação Infantil. In: VIII CONGRESSO DE PROFESSORES DO ENSINO SUPERIOR DA REDE SINODAL, 2019, Joinville. Anais... Joinville: Faculdade IELUSC, 2019, p. 1-13.

LORENZATO, Sérgio. Educação Infantil e percepção matemática. 3 ed. Campinas: Autores Associados, 2011.

LÜDKE, Menga Alves; ANDRÉ, Marli. Pesquisa em Educação: abordagens qualitativas. São Paulo: EPU, 1986.

OLIVEIRA, Joana Angélica Bernardo de. Formação de professores, competências e saberes para atividade docente na Educação Infantil. 2006. Revista Ibero-Americana de Estudos em Educação, Araraquara, v. 1, n. 1, p. 113-122, 2006.

PASCHOAL, Jaqueline Delgado; MACHADO, Maria Cristina Gomes. A história da educação infantil no Brasil: Avanços, retrocessos e desafios dessa modalidade educacional. Revista HISTEDBR On-line, Campinas, v. 9, n. 33, p. 78-95, mar. 2009.

REAME, Eliane; RANIERI, Anna Claudia; GOMES, Liliane; MONTENEGRO, Priscila. Matemática no dia a dia da Educação Infantil: rodas, cantos, brincadeiras e histórias. São Paulo: Saraiva, 2012.

SAIZ, Irma Elena. A direita... de quem? Localização espacial na Educação Infantil e nas séries iniciais. In: PANIZZA, Mabel (Org). Ensinar Matemática na Educação Infantil e nas Séries Iniciais. Tradução de Antonio Feltrin. Porto Alegre: Artmed, 2006, p. 143-167.

SANTOS, Nathalia Fernanda Ribeiro dos. Educação Infantil no Brasil: o paradigma entre o cuidar e o educar no Centro de Educação Infantil. 2010. 41f. Trabalho de Conclusão de Curso (Licenciatura em Pedagogia) - Centro de Educação, Comunicação e Artes. Universidade Estadual de Londrina. Londrina.

SILVA, Maria Cristina Dias de Souza. O processo histórico da Educação Infantil: um olhar reflexivo a partir da realidade de Capivari do Sul. 2010. 63f. Dissertação (Mestrado em Teologia). Escola Superior de Teologia. São Leopoldo.

SILVEIRA, Adrienne Galvão; SAMPAIO, Adriany de Ávila Melo. O cuidar e o educar na Educação Infantil: uma perspectiva para graduados em licenciaturas. In: II SEMINÁRIO DE PESQUISA DO NUPEPE, 2010, Urbelândia. Anais... Urbelândia: UFU, 2010, p. 28-35.

SMOLE, Kátia Cristina Stocco. A Matemática na Educação Infantil: a teoria das inteligências múltiplas na prática escolar. Porto Alegre: Penso, 2000. 